\title{
Mauro Vega Bendezú, Discursos sobre “raza” y nación en Colombia, 1880-1930,
}

Cali: Universidad del Valle, 2013,242 p.

\section{Por: Viviana Arce Escobar}

Coordinadora Educativa y Cultural de los Museos Colonial y Santa Clara del Ministerio de Cultura (Bogotá). Magíster en Historia de la Universidad de los Andes y Licenciada en Historia de la Universidad del Valle. Correo electrónico:varce@mincultura.gov.co.

El libro Discursos sobre "raza" y nación en Colombia, 1880-1930 de Mauro Vega Bendezú se concentra en estudiar los discursos y las representaciones sobre la "raza”, la etnicidad y la nación en Colombia, entre finales del siglo XIX e inicios del XX. Para hacerlo, no obstante, el autor trasciende estas cuatro décadas, y presenta una historia de la larga duración, en la que los grupos étnicos subalternos, llámense indios o negros, sufren un proceso de "otrorización" al ser invisibilizados, reprimidos y despreciados. En el periodo colonial, el indígena fue presentado como "idólatra" o "buen salvaje" y en los siglos XIX y XX como "raza inferior", "degenerado" o pobre, lo que significa que la alteridad no es exclusiva del periodo de la Regeneración, sino que debe entenderse en el marco de su "espacio de experiencia". Solo que desde la Regeneración (1886) y hasta los años treinta del siglo XX, nos dice el autor:

Se experimentaron diferentes prácticas y discursos racistas que, por un lado, veían con odio y desprecio a los indígenas, y por oposición, veían con añoranza y nostalgia el legado español. De este modo, la élite intelectual colombiana construyó un metarrelato histórico y un universo simbólico de la nación a partir de la negación radical del otro y se imaginó un país sin indios y sin negros en el objetivo de construir una nación blanca. Para lograr este objetivo de desindianización se implementaron un conjunto de estrategias que iban desde la eliminación simbólica del otro (en los relatos de la nación y en las celebraciones públicas), hasta su asimilación cultural (vía la evangelización y la educación) y biológica (vía la eugenesia y la inmigración europea). ${ }^{1}$

Como lo ha señalado el profesor Álvaro Villegas Vélez, en Colombia es poca la producción historiográfica que se concentra en analizar los discursos que se han ocupado por describir, prescribir y

1 Mauro Vega Bendezú, Discursos sobre “raza” y nación en Colombia, 1880-1930 (Cali: Universidad del Valle, 2013), 11. 
proscribir las alteridades raciales ${ }^{2}$. El libro de Vega Bendezú viene a nutrir esa escasa bibliografía, preocupándose por abarcar temas que hasta el momento habían sido trabajados de forma fraccionada.

A partir de los conceptos de "episteme" y "prácticas discursivas" del historiador francés Michel Foucault, Vega Bendezú logra desentrañar los discursos proferidos por Miguel Antonio Caro, Jorge Isaacs, Luis López de Mesa, Miguel Jiménez López, entre otros. El autor encuentra que estos metarrelatos no fueron expresados y entendidos como verdades absolutas exclusivamente en el campo académico e intelectual del país, sino que traspasaron los muros de las universidades para convertirse en los discursos oficiales del Estado y de la Iglesia.

Como lo señala el mismo autor, mientras la episteme proporciona las claves para interpretar y explicar la realidad, el concepto de estrategias de poder brinda los medios e instrumentos para actuar e intervenir sobre ella ${ }^{3}$. Así, a partir de otras fuentes como las celebraciones públicas o los informes presentados a las gobernaciones con más afluencia de población indígena (como por ejemplo Popayán,), Vega Bendezú logra demostrar que estos discursos no fueron exclusivos del campo simbólico, sino que traspasaron las fronteras de las prácticas cotidianas.

Esta perspectiva analítica acerca este libro a los trabajos de Brooke Larson ${ }^{4}$, Carlos Andrés Charry $^{5}$ y Patricia D’Allemand ${ }^{6}$, quienes han mostrado cómo se constituyó tempranamente todo un discurso sobre el mestizaje por parte de las élites. La mezcla racial y cultural fue considerada fundamental para la integración de la población y para evitar los conflictos y guerras entre grupos diferenciados de la sociedad. No obstante, estos autores se han ocupado de procesos de racialización vinculados a lo afro (negros, zambos y bogas ${ }^{7}$, mientras que Vega Bendezú abarca lo étnico en general y lo indígena en particular.

Por otra parte, Vega Bendezú también se aproxima a los discursos sobre las diferencias poblacionales y regionales. En este caso, el autor encuentra afinidad con las investigaciones de Margarita Ser$\mathrm{je}^{8}$ y Peter Wade ${ }^{9}$, quienes han develado los discursos sobre las capacidades de progreso, moralidad y prosperidad de ciertas regiones. Sin embargo, Vega Bendezú va más allá al incorporar estos discursos

2 Álvaro Villegas Vélez, "Alteridad racial y construcción nacional: un balance de los estudios sobre las relaciones entre raza y nación en Colombia”, Universitas Humanística, 77 (2014) 305-325.

3 Mauro Vega Bendezú, Discursos sobre “raza” y nación en Colombia, 15.

4 Brooke Larson, Indígenas, elites y Estado en la formación de las repúblicas andinas (Lima: Pontificia Universidad Católica del Perú e Instituto de Estudios Peruanos, 2002).

5 Carlos Andrés Charry Joya, "Los intelectuales colombianos y el dilema de la construcción de la identidad nacional (18501930)", Revista Europea de Estudios Latinoamericanos y del Caribe (2011): 55-70.

6 Patricia D’Allemand, "Rediseñando fronteras culturales: mapas alternativos para la historiografía literaria latinoamericana", Literatura, Teoría, Historia, Crítica, 4 (2003): 79-104.

7 Álvaro Villegas Vélez, "Alteridad racial y construcción nacional”, 313.

8 Margarita Serje, El revés de la nación. Territorios salvajes, fronteras y tierra de nadie (Bogotá: Universidad de Los Andes, 2005).

9 Peter Wade, Música, raza y nación: música tropical en Colombia (Bogotá: Vicepresidencia de la República, Departamento Nacional de Planeación, 2002). 
regionales en un marco más amplio de interpretación, contrastándolos con los discursos de carácter nacional. Además de articular toda esta amalgama de metarrelatos, Vega Bendezú se apropia del concepto de "nación católica”, acuñado por María Emma Wills ${ }^{10}$ (2000), para incorporar una institución obviada por los otros autores mencionados: la Iglesia.

Al vincular los discursos raciales proferidos por políticos e intelectuales con las medidas adoptadas por la Iglesia católica para “reconquistar” y “reevangelizar” a los indígenas olvidados por el Estado, Vega Bendezú contribuye de manera novedosa con el debate historiográfico. En esa medida, como lo señala el mismo autor: "el libro no pretende volver a trazar la historia del pensamiento político colombiano, sino que desea mostrar las posturas, los enfoques, los debates y las estrategias narrativas de la otrorización, a partir de la idea de que los discursos racialistas expresan la conjugación de saberes, esquemas de poder, normatividades y subjetividades singulares"11.

El interés fundamental en este objeto de estudio parte del hecho de que, según el autor, la historiografía colombiana del siglo XX no se ha preocupado por el "otro étnico" como sujeto y objeto de indagación. El concepto de etnicidad es prácticamente nulo en las investigaciones históricas y aunque desde la década de los 60 del siglo pasado comenzaron a llegar al país corrientes tales como la Escuela de los Annales, la historia social marxista y la microhistoria italiana, esto no ha generado mayor preocupación por abarcar los temas relacionados con las alteridades raciales. Esta ausencia sistemática del otro la atribuye Vega Bendezú a dos factores:

En primer lugar, "a las imágenes sedimentadas en subjetividades, experiencias y narrativas, en tanto que encierran un contenido relacional jerárquico (entre clases, grupos y etnias) y son portadoras de mensajes específicos emitidos por clases, grupos, sistemas culturales e ideológicos que pertenecen a una formación histórica”12 y, en segundo lugar, al éxito del historicismo y el liberalismo, que al poner en primer plano a los documentos de archivo y a los individuos, respectivamente, han producido un conocimiento particular del pasado.

Con el propósito entonces de ir solventando esa ausencia del otro étnico en los relatos historiográficos, Vega Bendezú estudia las alteridades raciales identificando la matriz discursiva o las huellas textuales coloniales en los discursos políticos, científicos y etnográficos de finales del siglo XIX y principios del XX. Para hacerlo, se apoya principalmente en los aportes de Homi Bhabha, quien se ha preocupado por desentrañar la autoridad y el poder que subyacen en los relatos y narraciones, dado que ellos promueven su legitimidad y un sistema jerárquico de valores.

10 María Emma Wills Obregón, "De la nación católica a la nación multicultural: rupturas y desafíos en la Constitución de 1991", en Museo, memoria y nación, Gonzalo Sánchez, y María Emma Wills Obregón, compiladores, Museo, memoria y Nación. Misión de los museos nacionales para los ciudadanos del futuro. (Bogotá: Ministerio de Cultura, IEPRI, PNUD, ICANH y Museo Nacional, 2000).

11 Mauro Vega Bendezú, Discursos sobre "raza” y nación en Colombia, 12.

12 Mauro Vega Bendezú, Discursos sobre “raza” y nación en Colombia, 17-18. 
El primer capítulo es seguramente la mayor contribución que brinda el libro de Mauro Vega. Titulado "la escritura de la historia: epistemología, eurocentrismo y alteridad", abarca todo un debate historiográfico en torno a Michel Foucault, Homi Bhabha, Spivak, Dispesh Chakravorty y Edward Said. En este apartado se pone sobre la mesa los debates acerca de la escritura histórica eurocéntrica, las limitantes que aparecen al estudiar los "pasados subalternos", los inconvenientes de representación de los textos “orientalistas" y el impacto del racismo en la construcción de alteridades raciales.

El autor logra demostrar en este capítulo que durante el contexto de 1880 a 1930 coexistieron diferentes regímenes de "verdad” en los textos modernos, avalados en los datos del "archivo" colonial. Es decir, los discursos racistas y racialistas proferidos por científicos, abogados y políticos eran irrefutables porque los documentos coloniales soportaban su validez. Con esto, Vega Bendezú muestra la articulación entre matrices discursivas, escritura de la historia y celebraciones públicas, dado que estos mensajes no se quedaban exclusivamente en el campo simbólico, sino que se materializaban en las actividades cotidianas.

En este punto, Vega Bendezú hace una fuerte crítica a la historiografía colombiana, que se ha preocupado más por el concepto de nación que por el de etnicidad. A pesar de que la bibliografía sobre el tema de la nación es amplísima en nuestro país, el de etnicidad brilla por su ausencia. En Colombia, las corrientes historiográficas como la "historia desde abajo" o los "estudios subalternos", aunque se han convertido en una alternativa a la escritura de la historia tradicional, no han tenido el peso y aval que sí han logrado la historia política o económica.

En el segundo capítulo, titulado “La ‘nación católica’, raza y religión: el discurso moral”, Mauro Vega hace todo un análisis de los discursos proferidos por Miguel Antonio Caro, uno de los grandes artífices del periodo de la Regeneración. Aunque Caro ha sido estudiado con cierta frecuencia, el gran aporte del libro es destacar la noción de una moral cristiana, que no solo sirvió a las élites para autoafirmarse en su superioridad racial, sino que también ayudó a implementar un proyecto político elitista, autoritario y neocorporativo. "En este sentido - dice el autor-la Regeneración también puede entenderse como un proyecto racial que intentó reorganizar y redistribuir los recursos del Estado siguiendo determinados patrones raciales (binomio blanco-no blanco)"13. De esta manera, al igual que había ocurrido en el periodo colonial, el Estado y la Iglesia católica trabajaron de la mano para sacar adelante un proyecto hispanista que culpaba el fracaso de la nación a la supuesta inferioridad racial y a la falta de mayor mestizaje con linajes europeos.

El tercer capítulo llamado "El Estado y las periferias: el discurso etnográfico", se enfoca en reconstruir la visión y las políticas que el Estado colombiano impulsó para evangelizar los llamados

13 Mauro Vega Bendezú, Discursos sobre “raza” y nación en Colombia, 63. 
“territorios salvajes". Aquí el autor trae a colación un acalorado debate entre Miguel Antonio Caro y Jorge Isaacs con respecto a este tema. Lo interesante de este apartado es que aunque Caro se presenta como un hispanista e Isaac como un proindigenista, ambos terminan teniendo posturas racistas frente al indígena. Mientras Caro se sostiene en la retórica evangelizadora de la Iglesia católica colonial, Isaacs avala sus argumentos en las Crónicas de Indias y en la literatura de viajes. No obstante, ambos continúan reproduciendo la idea de reducir a los "salvajes". En últimas, el discurso etnográfico operó - dice el autor "como proveedor de imágenes de alteridad que profundizaron las diferencias culturales y raciales. Así, los estereotipos y prejuicios coloniales se actualizaron a partir de nuevos registros, evidencias y lenguajes que estaban demostrando efectivamente la inferioridad del indio" 14 .

El cuarto capítulo, denominado “'Raza', etnicidad y modernización: el discurso científico I”, retoma los escritos y discursos proferidos por el médico psiquiatra Luis López de Mesa, para señalar cómo el discurso "científico" empezó a elaborar un visión claramente racista del país. El darwinismo, la eugenesia y el positivismo entraron en escena durante las primeras tres décadas del siglo XX para crear clasificaciones y categorías para la población según su "raza”. Nuevamente aquí la base argumental se encuentra en los antecedentes coloniales, trayendo a colación frases como "sangre noble" o "limpieza de sangre".

Aunque López de Mesa y sus textos sobre la "los problemas de la raza” también han sido estudiados por otros autores, Vega Bendezú enmarca estos discursos “científicos” en el debate sobre los conceptos de "raza" y "etnicidad". Los términos de "raza” y "etnicidad” no han sido valorados ni usados por la historiografía colombiana, a diferencia, por ejemplo, de México, Ecuador, Bolivia, Brasil y Perú. Estos conceptos han sido de más interés para disciplinas afines tales como la antropología o la arqueología, donde los trabajos de Carl Langebaek son los más destacados.

Según el autor, la omisión de estos conceptos en la escritura de la historia colombiana se debe a dos motivos: en primer lugar, "porque supuestamente dan cuenta de experiencias sociales tradicionales y arcaicas, donde no existen individuos" y, en segundo lugar, "porque se tiene la convicción de que la condición étnica subalterna representa una minoría en un país predominantemente mestizo y blanco, tópico común que considera que los grupos étnicos desde el siglo XVI forman parte de un proceso de mestizaje e hibridación [...], donde todos terminan siendo absorbidos por la "raza" blanca dada su superioridad innata” ${ }^{15}$. Esta es una hipótesis poderosa en todo el libro y la razón principal para contribuir a esta escasa bibliografía sobre la etnicidad en el campo historiográfico.

14 Mauro Vega Bendezú, Discursos sobre "raza” y nación en Colombia, 107.

15 Mauro Vega Bendezú, Discursos sobre “raza” y nación en Colombia, 145-146. 
Finalmente, en el quinto capítulo, intitulado "El debate sobre la degeneración racial: el discurso científico II”, el autor devela el debate sobre la degeneración racial en Colombia. Científicos de la talla de Miguel Jiménez López sostuvieron que los pobres en general y los indígenas en particular se encontraban en un estado avanzado de degeneración racial y moral, razón por la cual la nación no "progresaba". En ese caso, se tomaron medidas médicas, como la eugenesia y la higienización, y educativas para "purificar" y "blanquear" el país.

El autor deja claro que el discurso científico de inicios del siglo XX, encabezado por López de Mesa y Jiménez López, no desplazó el pensamiento hispanista de base católica de Caro y ni el de "buen salvaje" de Isaacs, de finales del siglo XIX. Estos discursos coexistieron y justificaron las nuevas teorías evolutivas y eugenésicas que intentaban acelerar el proceso de blanqueamiento del país.

En este punto, Vega Bendezú se aparta de la tesis de Zandra Pedraza, quien ha sostenido que la noción de degeneración de la raza surgió en Colombia producto del desencanto y pesimismo que sufría el país por el legado de la Regeneración. Para el autor, no son discursos contraproducentes, sino que todos hacen parte de una misma matriz discursiva que intentaban a toda costa acabar con los grupos étnicos. Solo entendiendo que todos estos discursos, a pesar de su origen disciplinar o contextual, hacen parte de un mismo andamiaje, es que se puede comprender que el mestizaje no es otra cosa que una falacia que nos ha vendido la idea de lo integrador, armonizador y democratizador que es Colombia, cuando en el fondo esos mismos discursos develan un racismo latente y un deseo profundo y constante de blanqueamiento.

Es por todo esto que Discursos sobre la raza y nación en Colombia, 1880-1930 se convierte en una lectura obligatoria y necesaria para todos aquellos interesados en estudiar las alteridades raciales y la construcción de la nación. 